\title{
Danos causados por bovinos em diferentes espécies arbóreas recomendadas para sistemas silvipastoris
} \author{
Adelino Pelissari², Paulo César de Faccio Carvalho ${ }^{4}$ \\ ${ }^{1}$ Embrapa Florestas, Estrada da Ribeira, Km 111, CP 319, CEP 83411-000, Colombo, PR, Brasil \\ ²Universidade Federal do Paraná, CP 19061, CEP 81531-990, Curitiba, PR, Brasil \\ ${ }^{3}$ Instituto Agronômico do Paraná, Estação Experimental Fazenda Modelo, CP 129, CEP 84001-970, Ponta Grossa, PR, Brasil \\ ${ }^{4}$ Universidade Federal do Rio Grande do Sul, CP 776, CEP 91501-970, Porto Alegre, RS, Brasil
}

Vanderley Porfírio-da-Silva ${ }^{1}$, Anibal de Moraes $^{2}$, José Luis Moletta ${ }^{3}$, Laíse da Silveira Pontes ${ }^{3}$, Edilson Batista de Oliveira ${ }^{1}$,

*Autor correspondente:

porfirio@cnpf.embrapa.br

Termos para indexação:

Mastigação de casca

Ramoneio

Arborização de pastagens

Integração pecuária-floresta

Agrossilvipastoril

Index terms:

Chewing bark

Browsing

Afforestation of pasture

Tree-livestock integration

Agroforestry

\begin{abstract}
Resumo - Três espécies arbóreas foram avaliadas quanto aos danos causados por bovinos em pastejo em um sistema silvipastoril implantado na região subtropical do Brasil. As espécies Schinus terebinthifolius (Raddi), Grevillea robusta (A. Cunn. ex R.Br) e Eucalyptus dunnii (Maiden), foram plantadas em linhas simples, arranjadas em 14 m x 3 m, para comporem um sistema agrossilvipastoril. Durante os primeiros três anos a área foi utilizada para produção de grãos em sistema de cultivo em aléias (silviagrícola). Após 41 meses do plantio das árvores, o gado foi introduzido pela primeira vez na área. Cinco classes de intensidade de danos foram estabelecidas: sem dano, baixa, média, alta e extrema. Os danos causados à casca do tronco das árvores no sistema foram maiores do que os causados às copas. As árvores de $S$. terebinthifolius foram as mais danificadas pelos bovinos. A manutenção de $S$. terebinthifolius em sistema silvipastoril não é recomendada pelo dano que o gado impõe às árvores.
\end{abstract}

Histórico do artigo: Recebido em 28/11/2011 Aprovado em 26/04/2012 Publicado em 29/06/2012 doi: $10.4336 / 2012 . p f b .32 .70 .67$

\section{Damages caused by cattle on different tree species in silvopastoral systems}

\begin{abstract}
We assessed the damage done by cattle in three species of trees in a silvopastoral system implanted in the subtropical region of Brazil. The species Schinus terebinthifolius (Raddi), Grevillea robusta (A. Cunn. Ex R. Br) and Eucalyptus dunnii (Maiden), were planted in single rows $(14 \mathrm{~m} \times 3 \mathrm{~m}$ ) to compose a silvopastoral system. During the first three years, the area was used for grain production in alley cropping systems. After 41 months of planting trees cattle were first introduced in the area. Five classes of damage intensity were established: no damage, low, medium, high, and extreme. The damage to the bark of trees were larger than those caused to the crown. The trees of $S$. terebinthifolius were more damaged by cattle. The maintenance of $S$. terebinthifolius trees in silvopastoral system is not recommended because the damage done by cattle is of extreme intensity.
\end{abstract}

\section{Introdução}

Para a implantação de um sistema silvipastoril, o estabelecimento das árvores constitui-se em uma fase crítica, pois os danos causados pelo gado, neste período, pode comprometer o sucesso do sistema (Ribaski, 1986;
Sharrow, 2001; Lehmkuhler et al., 2003). Este fato gerou a busca por mecanismos que pudessem contornar o assédio dos animais às árvores na fase juvenil, tais como substâncias repelentes (Eason et al., 1996; Lehmkuhler et al., 2003; Barrios et al., 2004) e proteção física (Montoya \& Baggio, 1992; Eason et al., 1996). 
Além disso, estratégias de implantação, como a execução de uma fase silviagrícola, até que as árvores tenham porte suficiente para suportar o assédio animal, quer seja por roçar o corpo nos troncos, quer seja por não mais alcançar os galhos e ramos troncos, quer seja por não mais alcançar os galhos e ramos da árvore, são recomendadas e têm sido utilizadas (Carvalho et al, 2002; Garret et al., 2004; Reis et al., 2007).

O sucesso de um sistema silvipastoril depende da adaptabilidade da forrageira para com o ambiente sombreado (Schreiner, 1987; Castro et al., 1999; Paciullo et al., 2009; Varella et al., 2009), do estabelecimento adequado das árvores (Fike et al., 2004; Porfírio-daSilva \& Moraes, 2010) e da compatibilidade do tipo e da categoria animal para com as árvores e com a forrageira (Silva et al., 2001; Fike et al., 2004). Em geral, ovinos e caprinos são mais propensos a comer ramos, folhas e cascas de árvores, enquanto que os bovinos quebram ramos, galhos e troncos de árvores jovens que ainda não suportam a carga do corpo do animal (Bendfeldt et al., 2001; Fike et al., 2004;). Em ambos os casos, essas ações do gado podem comprometer o estabelecimento adequado das árvores, o que dificulta a implantação do sistema silvipastoril.

Os registros de danos causados por bovinos em árvores já estabelecidas são recorrentes em afirmar que são de pequena monta ou mesmo negligenciáveis, desde que as árvores tenham porte para suportar o assédio dos animais (Lewis et al., 1983; Couto et al.,1994; Baggio \& Schreiner, 1988; Silva et al., 2001; Fike et al., 2004). Porém, em estudo realizado no Paraná, foram registrados níveis de danos preocupantes causados por bovinos pelo corte na casca e no tecido cambial/lenho de árvores de E. grandis de três anos de idade em um sistema silvipastoril com braquiária (Brachiaria brizantha $\mathrm{cv}$. Xaraés) (Medrado et al., 2009).

Quando uma árvore tem a casca "roída", pode aumentar a chance de mortalidade pois, sem a casca, a árvore perde parte importante de suas defesas contra doenças (Ferreira, 2001; Ferreira \& Milani, 2004) e insetos. A exposição do lenho favorece o ataque de fungos e insetos xilófagos que podem promover o apodrecimento e provocar a quebra do tronco. Efeitos conhecidos como a acumulação de fotoassimilados acima da área lesionada ( $\mathrm{Li}$ et al., 2003) e esgotamento das reservas de amido da raiz (Högberg et al., 2001) podem promover o aumento temporário da respiração do solo (Nordgren et al., 2003). A acumulação de fotoassimilados, como amido, acima da região onde a casca foi mastigada (roída) pode aumentar as chances da árvore ser novamente procurada pelos animais, resultando em danos crescentes e mortalidade da árvore.

Forragens herbáceas, especialmente gramíneas, constituem a principal fonte de alimentos para bovinos (Bóo et al., 1993; Lima et al., 1998; Santos et al., 2002), embora esses animais apreciem maior variedade em sua dieta (Santos et al., 2002; USDA, 2005). Em ambiente pastoril onde existam árvores, os animais vão consumir pequenas quantidades de ramos e folhas a cada dia, se estas estiverem acessíveis (Lima et al., 1998; Santos et al., 2002; Fike et al., 2004). Tal consumo pode tornarse problema no sistema silvipastoril quando a pequena quantidade de ingestão diária, acumulada, atinge níveis de dano inaceitáveis para o crescimento das árvores.

O interesse por sistemas integrados de produção vem crescendo entre produtores, acadêmicos, pesquisadores e formadores de política pública (Simpósio..., 2007; Brasil, 2011). A busca e avaliação dos componentes agrícola, pecuário e florestal, adequados, são fundamental para o alcance da potencialidade dos sistemas agrossilvipastoris.

A aroeira (S. terebinthifolius Raddi) é uma árvore perenifólia de crescimento moderado (até $12 \mathrm{~m}^{3} \mathrm{ha}^{-1}$ ano $^{-1}$ ), podendo atingir até $10 \mathrm{~m}$ de altura e até $30 \mathrm{~cm}$ de DAP; tem ocorrência natural em várias tipologias florestais, tolerando muitos tipos de solo (Carvalho, 1994; 2003). É resistente a geadas (Carvalho, 1981) com hábito de crescimento simpodial. A aroeira tem usos como madeira para diversos fins, extração de tanino, paisagismo (Carvalho, 2003; Williams et al., 2005), medicinal no tratamento de inflamações (Amorin \& Santos, 2003), cicatrizante (Bacchi, 1986; Martínez et al., 1996; Lucena et al., 2006), além de apresentar ação antimicrobiana (Lima et al., 2004; Santos et al., 2010) e antioxidante (Velázquez et al., 2003; Degáspari, 2004). É consumida por caprinos e não é assediada e nem pastejada pelo gado bovino (Baggio, 1988), sendo indicada para a arborização de pastos (Montoya et al., 1994; Carvalho, 1994). Não obstante, resultados práticos e, ou, de pesquisas envolvendo esta espécie em sistemas silvipastoris ainda são desconhecidos.

A grevílea (G. robusta A. Cunn. ex R.Br.) é espécie semidecídua, heliófila, de crescimento moderado a rápido $\left(20 \mathrm{~m}^{3} \mathrm{ha}^{-1} \mathrm{ano}^{-1}\right.$ a $\left.33 \mathrm{~m}^{3} \mathrm{ha}^{-1} \mathrm{ano}^{-1}\right)$, podendo atingir até $35 \mathrm{~m}$ de altura e DAP de $80 \mathrm{~cm}$ (Harwood, 1992; Embrapa, 1986). Com hábito de crescimento monopodial, que se adapta a diferentes condições 
edafoclimáticas e apresenta tolerância a geadas leves quando adulta (Fritzsons et al., 2010). Os principais usos dessa espécie incluem ornamentação, produção de serapilheira, mel, quebra-ventos, madeira para fins diversos, e sombreamento de culturas agrícolas e pastagens (Martins \& Medrado, 2003). A utilização da grevílea para arborização de pastagens (sistemas silvipastoris) no Brasil foi registrada pela primeira vez em 1985 por Gonçalvez et al. (Porfírio-da-Silva, 1994), na região noroeste do estado do Paraná. Atualmente é a segunda espécie mais utilizada para arborização de pastagens no Paraná, (Menarim Filho, 2005).

$\mathrm{O}$ eucalipto (E. dunnii Maiden) é uma espécie tolerante a geadas (Higa et al., 2000) e por isso tem sido recomendada para plantios nas condições subtropicais brasileiras (Carpanezzi, 1986; Paludzyszyn et al., 2006). De crescimento rápido, com cerca de $40 \mathrm{~m}^{3} \mathrm{ha}^{-1} \mathrm{ano}^{-1}$, tem sido recomendada para uso como quebra-ventos e sua madeira é própria para serraria (Shimizu \& Carvalho, 2000). Embora, a espécie seja indicada para uso em arborização de pastagens (Baggio, 1993; Montoya et al.,1994), resultados de pesquisa em sistemas silvipastoris ainda são desconhecidos.

O objetivo deste trabalho foi avaliar o impacto do gado bovino sobre as árvores ao ser introduzido em um ambiente pastoril arborizado. Três espécies arbóreas indicadas para sistemas silvipastoris foram avaliadas: aroeira, grevílea e o eucalipto.

\section{Material e métodos}

O experimento foi realizado em um sistema agrossilvipastoril implantado em outubro de $2006 \mathrm{com}$ mudas de árvores de eucalipto (E. dunnii Maiden), aroeiravermelha (S. terebinthifolius Raddi) e grevílea (G. robusta A. Cunn. ex R. Br.) na Estação Experimental Fazenda Modelo/Iapar, em Ponta Grossa, Paraná (2507'22" $\mathrm{S}$; 50 $03^{\prime} 01^{\prime \prime} \mathrm{W}$; e altitude de $953 \mathrm{~m}$ ). Ocupando 7,95 ha, o sistema silvipastoril foi implantado sobre solos classificados como Cambissolo Háplico Distrófico típico e Latossolo Vermelho Distrófico típico (Bognola $\&$ Fasolo, 2003), em classe de relevo entre 4 e 9\% de declividade com face de exposição Norte.

O clima da região, de acordo com a classificação de Köeppen, é do tipo Cfb subtropical úmido mesotérmico, com temperatura média anual de $17,6^{\circ} \mathrm{C}$, variando entre mínimas de $8,5^{\circ} \mathrm{C}$ e máximas de $24,3{ }^{\circ} \mathrm{C}$. A precipitação média é de $1.400 \mathrm{~mm}$ a $1.600 \mathrm{~mm}$ anuais, distribuída ao longo do ano, com leve declínio nos meses de abril a agosto (Iapar, 1994). A cobertura vegetal original das áreas era de "vegetação campestre" (Veloso et al., 1991).

As árvores foram plantadas em filas simples com as espécies intercaladas na mesma fila, em espaçamento de $14 \mathrm{~m}$ x $3 \mathrm{~m}$, alocadas transversalmente ao sentido predominante da declividade do terreno para promoção do controle do escorrimento superficial das águas de chuva, e para que o deslocamento de máquinas e de animais fosse predominantemente transversal ao sentido da declividade (Porfírio-da-Silva et al., 2009). Desde então, a área foi utilizada para a produção de lavouras de inverno (aveia preta - Avena strigosa Schreb) e lavouras de verão (soja - Glicine $\max$ (L.) Merr. e milho - Zea mays L.) em sistema de cultivo em aléias (silviagrícola).

Em novembro de 2009, conforme mapeamento das características químicas e físicas do solo, a área recebeu adubação corretiva do solo mediante a aplicação fracionada por hectare de: $260 \mathrm{~kg}$ e $350 \mathrm{~kg}$ de $\mathrm{K}_{2} \mathrm{O} ; 54 \mathrm{~kg}$ e $72 \mathrm{~kg}$ de $\mathrm{P}_{2} \mathrm{O}_{5}$; e, $900 \mathrm{~kg}, 1200 \mathrm{~kg}$ e $1400 \mathrm{~kg}$ de gesso agrícola. Em 19/12/2009 foi plantado o sorgo forrageiro cv. AG 2501C (Sorghum bicolor (L.) Moench x Sorghum sudanense (Piper) Stapf) nas aléias entre os renques arbóreos. $\mathrm{Na}$ adubação de plantio foram utilizados $300 \mathrm{~kg} \mathrm{ha}^{-1}$ do formulado NPK (4:14:8). Adubação de cobertura foi realizada na fase de perfilhamento com $180 \mathrm{~kg} \mathrm{ha}^{-1}$ de $\mathrm{N}$ na forma de uréia.

A área foi subdividida em seis piquetes de 1,3 \pm 0,3 ha cada, mediante o emprego de cerca elétrica. Em todos os piquetes os animais dispunham de água e sal mineralizado à vontade. Os animais eram da raça Purunã e foram distribuídos nos piquetes considerando-se o peso médio, de forma a manter a carga animal similar em todos os piquetes.

O pastejo foi iniciado em 27/01/2010 (39 dias após o plantio da forrageira, quando o pasto alcançou de $1,0 \mathrm{~m}$ a 1,2 $\mathrm{m}$ de altura), e foi manejado sob pastejo contínuo com taxa de lotação variável (Mott \& Lucas, 1952) para manter o pasto com altura média de $50-60 \mathrm{~cm}$. Na primeira semana, o pastejo foi realizado por quatro novilhos (peso médio de $262 \pm 4 \mathrm{~kg}$ ) e seis bezerros (peso médio de $147,4 \pm 4 \mathrm{~kg}$ ) por piquete. Na semana seguinte, cada piquete recebeu mais dez vacas (peso médio de 426 $\pm 10 \mathrm{~kg}$ ), sendo seis animais em 03/02/2010 e quatro animais em 09/02/2010.

Os danos da presença do gado sobre as árvores foi avaliado no período de 10 a 12/02/2010, ocasião em que as árvores apresentavam diâmetro médio à altura do peito 
(DAP) e altura média total de : 4,7 $\pm 0,86$ e 3,49 $\pm 0,72$ (aroeira-vermelha); 6,28 $\pm 0,54$ e 4,54 $\pm 0,25$ (grevílea); e 15,71 $\pm 1,35$ e 9,47 $\pm 0,49$ (eucalipto).

A oferta de forragem ( $\mathrm{kg}$ de matéria seca para cada $100 \mathrm{~kg}$ de peso vivo animal por hectare) foi calculada por meio da fórmula:

$\mathrm{OF}=(\mathrm{MF} \div \mathrm{n}+\mathrm{TAD}) * 100 \div \mathrm{CA}$

Onde: $\mathrm{MF}=$ massa de forragem $(\mathrm{kg}$ de matéria seca ha $\left.^{-1}\right)=[($ MF em 27/01/2010 + MF em 13/02/2010) $\div$ 2]; $\mathrm{n}=$ número de dias de pastejo até a avaliação de danos; TAD = taxa de acúmulo diário de forragem $(\mathrm{kg}$ matéria seca $\left.\mathrm{ha}^{-1} \mathrm{dia}^{-1}\right) ; \mathrm{CA}=$ carga animal média $(\mathrm{kg}$ $h^{-1}$ ) no período de pastejo considerado até a avaliação de danos nas árvores, equivalente ao somatório dos pesos médios de todos os animais presentes em cada piquete multiplicado pelo número de dias que cada animal permaneceu no piquete, dividido pelo número de dias do período de pastejo (16 dias, de 27/01/2010 a $12 / 02 / 2010$ ).

A massa seca de forragem inicial (MF) foi obtida mediante a coleta, aleatória, de três amostras de $1,0 \mathrm{~m}^{2}$ (delimitada por um quadrado de metal de 1,0 $\mathrm{m} \mathrm{x} \mathrm{1,0} \mathrm{m)}$ em cada piquete, cortadas rente ao solo. As amostras foram secas em secadores de ventilação forçada a $65^{\circ} \mathrm{C}$ até peso constante para a determinação da matéria seca (MS). Para a estimativa da TAD foi empregada a técnica de gaiolas de exclusão com triplo emparelhamento (Moraes et al., 1990). A diferença entre a massa seca de forragem colhida dentro das gaiolas no dia 13/02/2010 e a massa seca de forragem colhida fora das gaiolas no dia 27/01/2010 foi dividida pelo número de dias entre as avaliações (17 dias).

O delineamento experimental foi em blocos ao acaso, constituído por três tratamentos (espécies arbóreas) com seis repetições (piquetes). Em cada piquete, 21 árvores foram aleatoriamente selecionadas, sendo sete de cada espécie.

Os danos causados pelos animais foram tipificados em função das partes danificadas (incidência) na planta: $\mathrm{Tq}=$ quebra da haste principal ou tronco; $\mathrm{Tl}=$ lesão do tronco alcançando o lenho pela retirada do tecido cambial; $\mathrm{Gq}=$ quebra de galhos/ramos secundários; $\mathrm{Cl}$ = lesão de casca, sem alcançar o câmbio; $\mathrm{Rq}=$ quebra de ramos finos e forrageamento de folhas, ou ramoneio; e $\mathrm{Dl}=$ lesão maior do que $5 \mathrm{~cm}$ de diâmetro.

Um sistema de pesos e nota foi estabelecido para os diferentes tipos de danos: $\mathrm{Tq}=10,0 ; \mathrm{Tl}=4,0 ; \mathrm{Gq}=2,0$; $\mathrm{Cl}=1,5 ; \mathrm{Rq}=1,0 ; \mathrm{e}, \mathrm{Dl}=1,0 . \mathrm{O}$ critério adotado relacionou o tipo de dano e sua importância para o desenvolvimento futuro da árvore. A nota final para cada indivíduo é a soma dos respectivos danos incidentes, exceto para o caso do dano Tq (quebra do tronco), cuja incidência, independentemente da ocorrência de outros tipos de dano, tem nota máxima. A ocorrência dos danos Dl (lesão da casca maior do que $5 \mathrm{~cm}$ de diâmetro), Tl (lesão do tronco alcançando o lenho pela retirado do tecido cambial), e Gq (quebra de galhos/ramos secundários), estão sempre associados a outros danos. Por exemplo: para ocorrer o dano Tl, obrigatoriamente ocorrem os danos dos tipos $\mathrm{Cl}$ e $\mathrm{Dl}$, o que implica numa nota 6,5 e não 4 . Conforme o critério estipulado que relacionou o tipo de dano e sua importância para o desenvolvimento futuro da árvore, cinco classes de intensidade de dano (d) foram estabelecidas: $\mathrm{d}_{0}=$ nula $\left(\mathrm{d}_{0}=0\right) ; \mathrm{d}_{1}=$ baixa $\left(0<\mathrm{d}_{1} \leq 3\right) ; \mathrm{d}_{2}=$ média $\left(3<\mathrm{d}_{2} \leq 6\right)$; $\mathrm{d}_{3}=$ alta $\left(6<\mathrm{d}_{3}<10\right) ;$ e, $\mathrm{d}_{4}=$ extrema $\left(\mathrm{d}_{4}=10\right)$.

Os dados amostrais foram utilizados para descrever quantitativamente e qualificar o dano sofrido pelas diferentes espécies arbóreas. O teste $W$ (Shapiro-Wilk), aplicado às notas atribuídas ao tipos de danos, rejeitou a hipótese de que os mesmos teriam distribuição Normal; os dados foram, então, submetidos à transformação logarítmica.

A comparação entre as notas médias de cada espécie foi comparada pelo teste de Tukey a $5 \%$ de probabilidade.

\section{Resultados e discussão}

No momento da avaliação dos danos causados nas árvores, a carga animal média (CA) era de 3.222,6 $\pm 691,2$ de peso vivo por hectare $(\mathrm{kg} \mathrm{PV} \mathrm{ha-1)}$, com oferta média de forragem $(\mathrm{OF})$ de $4,5 \% \pm 0,8 \%$ para promover uma rápida colheita e rebaixamento do dossel da pastagem acumulada desde a emergência (39 dias de crescimento). Tal oferta de forragem pode ser considerada satisfatória para o consumo voluntário dos animais que, conforme a literatura, varia de 1,5\% a $2,7 \%$ do peso vivo em matéria seca por dia (Genro, 2000; National Research Council, 2000).

Apesar de todas as espécies terem sido danificadas pelos bovinos (Figura 1), foi observada diferença significativa pelo teste Tuckey $(\mathrm{P}<0,05)$ de danos entre elas (Tabela 1). A grevílea e o eucalipto tiveram 59\% e $50 \%$, respectivamente, de seus indivíduos danificados, e a aroeira teve danos em $100 \%$ dos indivíduos, não corroborando com as informações de que não seria 
consumida ou assediada pelo gado (Baggio, 1988). A intensidade de dano foi maior na aroeira, apresentando 15 vezes mais danos de classe $\mathrm{d}_{2}$ (média), 2 e 4 vezes mais danos de classe $\mathrm{d}_{4}$ (extrema) do que as espécies grevílea e eucalipto. Possíveis causas incluem a presença de animais adultos (mais pesados e altos), que estariam relacionados com danos de ramoneio $(\mathrm{Rq})$, quebra de galhos (Gq) e quebra de tronco (Tq) (Silva et al, 2001).

Da totalidade dos danos nas árvores, a aroeira responde por $59,7 \%$ e a grevílea e o eucalipto, por $19,9 \%$ e $20,4 \%$, respectivamente. A participação de cada tipo de dano na incidência do dano total ocorrido no sistema, teve influencia da espécie arbórea e deu-se na seguinte ordem relativa de grandeza: $\mathrm{Rq}>\mathrm{Cl}>\mathrm{Dl}$ $>\mathrm{Gq}>\mathrm{Tl}>\mathrm{Tq}$ (Figura 2).
A quebra do tronco (Tq) foi o dano de menor ocorrência no sistema $(3,7 \%)$, tendo maior participação da aroeira $(57,1 \%)$, seguido da grevílea $(28,6 \%)$ e do eucalipto $(14,3 \%)$. A quebra do tronco $(\mathrm{Tq})$ pode acontecer em árvores cujos troncos ainda não tenham resistência mecânica capaz de suportar a força que os animais empregam para coçar seus corpos, numa manifestação natural de defesa contra ectoparasitas ou de busca de conforto físico. Este tipo de dano determina a retirada/perda da árvore do sistema, comprometendo sistemas com baixa densidade arbórea. É provável que a presença de animais adultos tenha contribuído mais para este dano do que os animais jovens (de menor massa corpórea) (Silva et al, 2001). Neste estudo, todas as árvores que tiveram o tronco quebrado (Tq) apresentavam o DAP menor do que $6 \mathrm{~cm}$, já identificado como de maior risco por Porfírio-da-Silva et al. (2009).

Tabela 1. Danos causados por bovinos em três espécies arbóreas em um sistema silvipastoril e as respectivas dimensões médias de diâmetro a altura do peito (DAP) e de altura (H) das árvores, aos 41 meses, em sistema silvipastoril. EEFM/Iapar, Ponta Grossa, PR, 2010.

\begin{tabular}{cccc}
\hline Espécie & Dano $^{(\mathbf{1})}$ & DAP \pm DP (cm) & H $\pm \mathbf{D P}(\mathbf{m})$ \\
\hline Aroeira (Schinus terebinthifolius) & $4,2 \mathrm{a}$ & $4,70 \pm 0,86$ & $3,49 \pm 0,72$ \\
Grevílea (Grevillea robusta) & $1,2 \mathrm{~b}$ & $6,28 \pm 0,54$ & $4,54 \pm 0,25$ \\
Eucalipto (Eucalyptus dunnii) & $1,2 \mathrm{~b}$ & $15,71 \pm 1,35$ & $9,47 \pm 0,49$ \\
\hline
\end{tabular}

(') Nota atribuída aos danos observados. As médias, seguidas por letras idênticas na mesma coluna, não diferem estatisticamente pelo teste de Tukey (P<0,05).

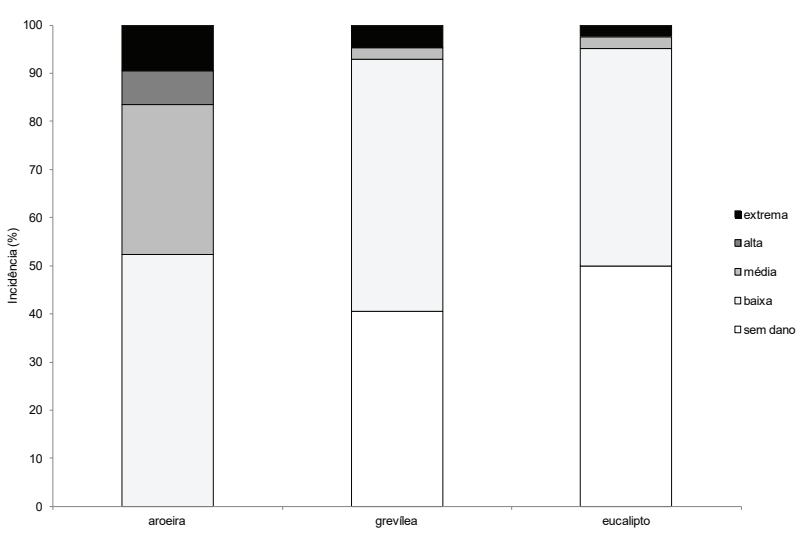

Figura 1. Incidência e intensidade de danos provocados por bovinos em três espécies de árvores em um sistema silvipastoril aos 41 meses de idade, na EEFM/Iapar, Ponta Grossa, PR, 2010.

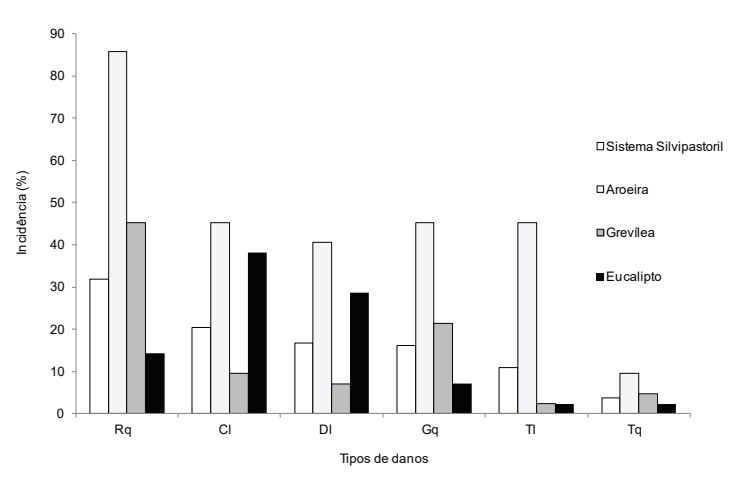

Figura 2. Tipos e incidência de danos causados pelos bovinos, no sistema silvipastoril e em cada uma das espécies arbóreas indicadas para sistemas silvipastoris: $\mathrm{Rq}=$ ramoneio; $\mathrm{Cl}=$ lesão de casca, sem alcançar o câmbio; $\mathrm{Dl}=$ lesão maior do que $5 \mathrm{~cm}$ de diâmetro; $\mathrm{Gq}=$ quebra de galhos; $\mathrm{Tl}$ = lesão do tronco alcançando o lenho; e, Tq = quebra do tronco. EEFM/Iapar, Ponta Grossa, PR, 2010. 
A quebra de ramos e ramoneio $(\mathrm{Rq})$ foi o dano de maior incidência no sistema (31,9\%), com a aroeira e a grevílea respondendo por $90 \%$ desse dano (Figura 2). Provavelmente porque tinham menor altura do que a espécie de eucalipto (Tabela1), favorecendo o acesso dos animais até os ramos e galhos. Embora as árvores tivessem sido desramadas até a metade de suas alturas, a desrama retirou os galhos mas não procedeu a desponte de galhos ou ramos pendentes, característicos de copas de árvores com hábito de crescimento simpodial como é a aroeira. Isso pode ter contribuído para a ocorrência de danos nos ramos e galhos, principalmente pelos animais maiores. Deste modo, surge um indício de que a fase silviagrícola deveria ser mais longa ou a desrama mais severa (mais alta), principalmente para a aroeira.

O ramoneio ou a mastigação de folhas e ramos finos $(\mathrm{Rq})$ de árvores em ambiente pastoril é esperado, principalmente se estas partes da árvore estiverem ao alcance dos animais (Silva et al., 2001; Santos et al., 2002; Lehmkuhler et al., 2003; Fike et al., 2004; Rangel et al., 2008) e apresentarem alguma qualidade forrageira. É um tipo de dano mais tolerável do que os demais, e pode ser contornado com a prática da desrama até uma altura em que os bovinos não possam alcançar os galhos e ramos, o que evita também a quebra de galhos $(\mathrm{Gq})$. No entanto, a mastigação da casca de árvores por bovinos é um dano incomum, não sendo encontrados relatos na literatura.

Os danos que lesionam a casca $(\mathrm{Cl}, \mathrm{Dl}$ e $\mathrm{Tl})$ atingem a estrutura que é responsável pelo principal componente de rendimento da árvore no sistema, ou seja, o tronco. A lesão do tronco alcançando o lenho (Tl) foi mais incidente na aroeira $(90,5 \%$ da totalidade do dano), o que pode ser indicativo da preferência dos animais pela espécie, mas também pode ser devido à espessura de casca menor do que a do eucalipto e a da grevílea. Cumulativamente, a aroeira teve grandes porções de casca retirada do tronco $(\mathrm{Dl}=45,7 \%)$ sem alcançar o câmbio $(\mathrm{Cl}=53,1 \%)$. Esse fato mostra que a fase silviagrícola mais longa favoreceria a aroeira somente contra danos na copa ( $\mathrm{Rq} \mathrm{e} \mathrm{Gq)} \mathrm{por} \mathrm{animais} \mathrm{adultos}$ (mais altos), mas não evitaria danos no tronco, que pode ser ocasionado por qualquer categoria animal.

No eucalipto os danos de maior incidência foram os do tipo $\mathrm{Cl}(41,0 \%)$ e $\mathrm{Dl}(37,5 \%)$, as lesões que alcançaram o lenho (Tl) participaram somente com $4,8 \%$ dos danos na espécie (Figura 2). É possível que em função da facilidade com que a casca do eucalipto é retirada do tronco (relativamente maior do que a da aroeira e a da grevílea) e por sua maior espessura, proporcionem maiores porções, por mordida/bocado, para ser mastigado, ao tempo que não requer mordida em sucessão contínua junto do tronco para obter determinada massa de casca, diminuindo a lesão no lenho (Tl) mas ampliando a lesão de casca (Dl e $\mathrm{Cl}$ ).

A retirada da casca pode promover a brotação de gemas epicórmicas, abaixo da região danificada. Entretanto, embora a brotação seja uma oportunidade para a sobrevivência da árvore, isso não é desejável num sistema silvipastoril onde as árvores foram escolhidas para fins madeireiros, pois o objetivo é ter um tronco único e alto, capaz de produzir uma tora.

Conforme Baxter \& Hansson (2001), mamíferos que comem cascas de árvores procuram, em diferentes espécies e, ou, sítios, balancear suas dietas por açúcar, minerais, ou proteína. Portanto, o dano dos bovinos às cascas de aroeira, eucalipto e grevílea, pode atuar como um indicador de comportamento no sistema silvipastoril em estudo. As espécies de árvores tem casca de espessura, textura e maciez diferentes, além de diferenças entre compostos químicos com apelo nutricional, como o amido, ou que podem inibir a mastigação da casca, como óleos essenciais e taninos condensados. Ashton (2005), avaliando os danos de equinos em casca de várias espécies de eucaliptos na Austrália, revela que existe seleção dos animais por árvores individuais, mostrando que, além de variação interespecífica existe a variação intra-específica, e que os danos foram maiores em árvores de maior diâmetro. No entanto, para ovinos, Eason et al. (1996) sugerem que o aumento do diâmetro reduz os danos por mastigação da casca das árvores. Embora não conclusivo, Ashton (2005), sugere haver uma ligação entre o teor de amido na casca e a mastigação da casca de eucaliptos pelos cavalos, podendo ser um fator de seleção das árvores que terão a casca consumida.

Estudos futuros poderão revelar se o conteúdo de amido, composição bromatológica e determinação de fibras e exsudatos das cascas, indicam preferência dos bovinos por uma espécie arbórea à outra (ou mesmo se ocorre preferência intraespecífíca), tal qual ocorre com equinos, conforme registrado por Ashton (2005). É importante observar que não se tem registros das características bromatológicas das cascas dos troncos dessas espécies. Novos estudos também poderão verificar qual seria o fator de atração para o consumo de 
casca de árvore, se existem características intrínsecas às arvores ou se é somente um desvio da conduta normal do comportamento ingestivo, provocado por algum fator de estresse social (Costa, 2003) ou de aprendizado prévio. Os animais utilizados no experimento são oriundos de criação extensiva a campo em pastagens características de campo nativo, onde a possibilidade de dieta diversificada é uma constante. A qualidade da forragem produzida e consumida pelo gado em sistema silvipastoril pode sofrer alterações (Carvalho et al., 1997; Andrade et al., 2003; Paciullo et al., 2009) e isto também deverá ser investigado para o entendimento do consumo de casca de árvores por bovinos em sistema silvipastoril.

Além disso, nas primeiras semanas de uma pastagem cultivada, é provável que os teores de fibra insolúvel em detergente neutro (FDN) sejam baixos e que o animal procure balancear sua dieta ingerindo pequenas quantidades diárias de folhas e ramos com maiores teores de FDN para equilibrar o mecanismo de consumo voluntário (Mertens, 1992). As folhas e ramos da aroeira e da grevílea, foram classificadas por Leme et al. (1994), como sendo de baixa qualidade forrageira, por apresentarem, ambas, acima de $60 \%$ de material não degradável na matéria seca (degradabilidade in vivo) e teores de taninos condensados acima de $10 \%$ para a aroeira e abaixo de $10 \%$ para a grevílea.

\section{Conclusões}

A espécie $S$. terebinthifolius não deve ser indicada para sistemas silvipastoris com o objetivo de obter produtos florestais da espécie.

$\mathrm{O}$ E. dunnii e a G. robusta podem ser utilizados como componentes arbóreos em sistemas silvipastoris nas condições subtropicais.

A desrama é uma prática silvicultural fundamental para o manejo de árvores em sistema silvipastoril, no entanto, não previne o impacto de danos causados por mastigação da casca do tronco das árvores.

As características como o DAP, a altura da inserção de copa proporcionada pela desrama, além daquelas intrínsecas à própria espécie (qualidade nutricional ou funcional), podem determinar a incidência e a intensidade de danos que serão causados pelo gado. Estudos sobre as características nutricionais e, ou, funcionais da casca, folhas e ramos de espécies arbóreas devem ser conduzidos para que seja possível referendar a escolha de determinada espécie para sistema silvipastoril.

\section{Agradecimentos}

Trabalho resultante do termo de cooperação técnica SAIC/AJU n ${ }^{\circ}$ 21500.10/0008-2 firmado entre IAPAR e Embrapa Florestas.

\section{Referências}

ANDRADE, C. M. S.; GARCIA, R.; PEREIRA, O. G.; SOUZA, A. L. Desempenho de seis gramíneas solteiras ou consorciadas com Stylozanthes guianensis, CV. Mineirão, em sistemas silvipastoris com eucaliptos. Revista Brasileira de Zootecnia, Viçosa, MG, n. 6, v. 32, suplemento 2, 2003.

AMORIN, M. M. R.; SANTOS, L. C. Tratamento de vaginose bacteriana com gel vaginal de Aroeira (Schinus terebinthifolius Raddi): ensaio clínico randomizado. Revista Brasileira de Ginecologia e Obstetrícia, Rio de Janeiro, n. 25, p. 95-102, 2003.

ASHTON, A. Bark chewing by the wild horses of Guy Fawkes River National Park, NSW: impacts and causes. 2005. 125 f. Monograph (Graduation in Science/Ecology) - University of New England, Armidale, New South Wales, Austrália.

BACCHI, E. M. Ação anti-úlcera e cicatrizante de algumas plantas brasileiras. Revista Brasileira de Farmacognosia, Curitiba, v. 1, p. 93-100, 1986.

BAGGIO, A. J. Alternativas para recuperação de solos degradados na região sul do país. In: SIMPÓSIO NACIONAL SOBRE RECUPERAÇÃO DE ÁREAS DEGRADADAS, 1992, Curitiba. [Anais...] Curitiba: UFPR, 1993. p. 126-131.

BAGGIO, A. J. A aroeira como potencial para usos múltiplos na propriedade rural. Boletim de Pesquisa Florestal, Colombo, n. 17, p. 25-32, dez. 1988.

BAGGiO, J. A.; SCHREINER, H. G. Análise de um sistema silvipastoril com Pinus elliottii e gado de corte. Boletim de Pesquisa Florestal, Colombo, n. 16, p. 19-29, dez. 1988.

BARRIOS, C.; BEER, J.; IBRAHIM, M. Pastoreo regulado y bostas del ganado para la protección de plântulas de Pithecolobium saman em potreros. Revista Agroforestería en las Américas, Turrialba. Disponível em: <http://www.fao.org /wairdocs/ LEAD/ X6332S / X6332S00.HTM>. Acesso em: 31 ago. 2004.

BAXTER, R.; HANSSON, L. Bark consumption by small rodents in the northern and southern hemispheres. Mammal Review, Oxford, n. 31, p. 47-59, 2001.

BENDFELDT, E. S.; FELDHAKE, C. M.; BURGER, J. Establishing trees in an Appalachian silvopasture: response to shelters, grass control, mulch, and fertilization. Agroforestry Systems, Dordrecht, n. 53, p. 291-295, 2001.

BOGNOLA, I. A.; FASOLO, P. J. Mapeamento dos solos e aptidão agrícola das terras da Fazenda Modelo - Ponta Grossa, PR. Colombo: Embrapa Florestas, 2003. (Relatório Final. Contrato de Coop. Técnica n.21500,02/0023-1).

BÓO, R. M.; LINDSTRON, L. I.; ELÍA, O. R.; MAYOR, M. D. Botanical composition and seasonal trends of cattle diets in central Argentina. Journal of Range Management, Denver, v. 46, n. 6, p. 479-482, 1993. 
BRASIL. Ministério da Agricultura Pecuária e Abastecimento. Programa ABC: agricultura de baixo carbono. Brasília, DF: MAPA, 2011. Disponível em: < http://www.agricultura. gov.br/abc > Acesso em: 05 set. 2011.

CARPANEZZI, A. A. (Coord.). Zoneamento ecológico para plantios florestais no Estado do Paraná. Brasília, DF: EMBRAPADDT; Curitiba: EMBRAPA-CNPF, 1986. 89 p. (Documentos, 17) .

CARVALHO, M. M.; SILVA, J. L. O. da; CAMPOS JÚNIOR, B. de A. Produção de matéria seca e composição mineral de forragem de seis gramíneas tropicais estabelecidas em um sub-bosque de angicovermelho. Revista Brasileira de Zootecnia, Viçosa, MG, v. 26, n. 2, p. 213-218, mar./abr. 1997.

CARVALHO, M. M.; ALVIM, M. J.; XAVIER, D. F.; YAMAGUCHI, L. C. T. Estabelecimento de sistemas silvipastoris: ênfase em áreas montanhosas e solos de baixa fertilidade. Juiz de Fora: Embrapa Gado de Leite, 2002. 12 p. (Embrapa Gado de Leite. Circular técnica, 68).

CARVALHO, P. E. R. Espécies arbóreas brasileiras. Brasília, DF: Embrapa Informação Tecnológica; Colombo: Embrapa Florestas, 2003. v. 1.1039 p.

CARVALHO, P. E. R. Competição entre espécies florestais nativas em Irati- PR, cinco anos após o plantio. Boletim de Pesquisa Florestal, Colombo, n. 2, p. 41-56, jun. 1981.

CARVALHO, P. E. R. Espécies arbóreas de uso múltiplo na Região Sul do Brasil. In: CONGRESSO BRASILEIRO SOBRE SISTEMAS AGROFLORESTAIS, 1., 1994, Porto Velho. Anais... Colombo: Embrapa-CNPF, 1994. v. 1. p. 289-320.

CASTRO, C. R. T.; GARCIA, R.; CARVALHO, M.; COUTO, L. Produção forrageira de gramíneas cultivadas sob luminosidade reduzida. Revista Brasileira de Zootecnia, Viçosa, MG, v. 28, n. 5, p. 919-927, 1999.

COSTA, M. J. R. P. Instalações: comportamento social dos bovinos e uso de espaço. In: ALENCAR, M. M. de; POTT, E. B. (Ed.). Sistemas de produção: criação de bovinos de corte na Região Sudeste. 2003. Disponível em: < http://sistemasdeproducao.cnptia. embrapa.br/FontesHTML/BovinoCorte/BovinoCorteRegiaoSudeste/ index.htm>. Acesso em: 13 ago. 2009.

COUTO, L.; ROATH, R. L.; BETTERS, D. R.; GARCIA, R.; ALMEIDA, C. C. Cattle and sheep in eucalypt plantations: a silvopastoral alternative in Minas Gerais. Agroforestry Systems, Netherlands, v. 28, n. 2, p. 173-184, 1994.

DEGÁSPARI, C. H. Propriedades antioxidantes e antimicrobiana dos frutos da aroeira Schinus therebentifolius Raddi. 2004. 102 f. Tese (Doutorado) - Universidade Federal do Paraná, Curitiba.

EASON, W. R.; GILL, E. K.; ROBERTS, J. E. Evaluation of antisheep tree-stem-protection products in silvopastoral agroforestry. Agroforestry Systems, Dordrecht, n. 34, p. 259-264, 1996.

FERREIRA, F. A.; MILANI, D. Avaliação de resistência de clones de eucalipto às infecções naturais de Cryphonectria cubensis, com nova metodologia. Revista Árvore, Viçosa, MG, v. 28, n. 2, abr. 2004.

FERREIRA, F. A. Portas de entrada para Cryphonectria cubensis em troncos de Eucalyptus citriodora e Eucalyptus grandis. Revista Árvore, Viçosa, MG, v. 25, n. 4, p. 513-519, 2001.
FIKE, J. H.; BURGER, A. L.; KALLENBACH, R. L. Considerations for establishing and managing silvopastures. Forage and Grazinglands, 2004. DOI:10.1094/FG-2004-1209-01-RV.

FRITZSONS, E.; CARPANEZZI, A. A.; WREGE, M. S.; AGUIAR, A. V. Zoneamento climático para grevílea (Grevillea robusta) para o Estado do Paraná. Pesquisa Florestal Brasileira, n. 61, p. 17-24, 2010. DOI: $10.4336 / 2010 . p f b .30 .61 .17$.

GARRET, H. E.; KERLEY, M. S.; LADYMAN, K. P.; WALTER, W. D.; GODSEY, L. D.; VAN SAMBEEK, J. W.; BRAUER, D. K. Hardwood silvopasture management in North America. Agroforestry Systems, Dordrecht, v. 61-62, n. 1-3, p. 21-33, 2004.

GENRO, T. C. M.; PRATES, E. R.; HERRERO, M.; SABATEL, V. Estimativa de consumo de bovinos em pastejo utilizando n-Alcanos como indicadores em gramíneas tropicais. In: REUNIÃO ANUAL DA SBZ, 37., 2000, Viçosa, MG. Anais. Viçosa, MG: SBZ, 2000.

HARWOOD, C. E. Natural distribution and ecology of Grevillea robusta in forestry and agroforestry. In: HARWOOD, C. E. (ed.). Grevillea robusta in agroforestry and forestry: proceedings of an international workshop. Nairobi: ICRAF, 1992. p. 21-28.

HIGA, R. C. V.; HIGA, A. R.; TREVISAN, R.; SOUZA, M. V. R. Resistência e resiliência a geadas em Eucalyptus dunnii Maiden plantados em Campo do Tenente, PR. Boletim de Pesquisa Florestal, Colombo, n. 40, p. 67-76, 2000.

HÖGBERG, P.; NORDGREN, A.; BUCHMANN, S. L.; TAYLOR, A. F. S.; EKBLAD, A.; HÖGBERG, M. N.; NYBERG, G.; OTTOSSON LOFVENIUS, M.; READ, D. J. Large scale forest girdling shows that current photosynthesis drives soil respiration. Nature, n. 411, p. 789-792, 2001.

IAPAR. Cartas climáticas do Estado do Paraná. Londrina, 1994. 44 p. (IAPAR. Série Documentos, 18).

LEHMKUHLER, J. W.; FELTON, E. E. D.; SCHMIDT, D. A.; BADER, K. J.; GARRET, H. E.; KERLEY, M. S. Tree protection methods during the silvopastoral-system establishment in midwestern USA: Cattle performance and tree damage. Agroforestry Systems, Dordrecht, v. 59, n. 1, p.35-42, 2003.

LEME, M. C. J.; DURIGAN, M. E.; RAMOS, A. Avaliação do potencial forrageiro de espécies florestais. In: MONTOYA, L. J.; MEDRADO, M. J. S. In: SEMINÁRIO SOBRE SISTEMAS AGROFLORESTAIS NA REGIÃO SUL DO BRASIL, 1., 1994, Colombo. Anais... Colombo: EMBRAPA-CNPF, 1994. p. 147-155. (EMBRAPA-CNPF. Documentos, 26).

LEWIS, C. E.; BURTON, G. W.; MONSON, W. G.; McCORMICK, W. C. Integration of pines, pastures, and cattle in south Georgia, USA. Agroforestry Systems, Dordrecht, n. 1, p. 277-297, 1983.

LI, C. Y.; WEISS, D.; GOLDSCHMIDT, E. E. Girdling affects carbohydrate-related gene expression in leaves, bark and roots of alternate-bearing citrus trees. Annals of Botany, London, n. 92, p. 137-143, 2003.

LIMA, E. O.; PEREIRA, F. O.; LIMA, I. O.; TRAJANO, V. N.; SOUZA, E. L. Schinus terenbenthifolius Raddi: avaliação do espectro de ação antimicrobiana de seu extrato aquoso. Infarma, v. 16, n. 7-8, p. 83-85, 2004. 
LIMA, J. A.; NASCIMENTO JUNIOR, D.; PEREIRA, J. C.; REGAZZI, A. J. Seletividade por bovinos em pastagem natural. 1. composição botânica. Revista Brasileira de Zootecnia, Viçosa, MG, v. 27, n. 3, p. 434-443, 1998.

LUCENA, P. L. H.; RIBAS FILHO, J. M.; MAZZA, M.; CZECZKO, N. G.; DIETZ, U. A.; CORREA NETO, M. A.; HENRIQUES, G. S.; SANTOS, O. J.; CESCHIN, A. P.; THIELE, E. S. Avaliação da Aroeira (Schinus terebinthifolius Raddi) na cicatrização de feridas cirúrgicas em bexiga de ratos. Acta Cirúrgica Brasileira, São Paulo, v. 21, p. 46-51, 2006.

MARTÍNEZ, M. J.; BETANCOURT, J.; ALONSO-GONZALEZ, N.; JAUREGUI, A. Screening of some Cuban medicinal plants for antimicrobial activity. Journal of Ethnopharmacology, v. 52, p. 171-174, 1996.

MARTINS, E. G.; MEDRADO, M. J. S. (Ed.). Sistema de produção: cultivo da grevílea nas regiões sul e sudeste do Brasil. 2003. Disponível em: < http://sistemasdeproducao.cnptia.embrapa. br/FontesHTML/Grevilea/CultivodaGrevileaSulSudeste/index.htm> Acesso em: 21 abr. 2010.

MEDRADO, M. J. S.; PORFIRIO-DA-SILVA, V.; DERETI, R. M.; FONSECA, L. R.; MAIER, T. F.; PINTON, A. L. M. Danos provocados em eucalipto por bovinos criados em sistema silvipastoril no município de Cruzmaltina, PR. Colombo: Embrapa Florestas, 2009. 8 p. (Embrapa Florestas. Comunicado técnico, 243)

MENARIM FILHO, A. Estratégia para a implantação de sistemas silvipastoris no Noroeste paranaense. Disponível em: <www. fundepecpr.org.br/palestras/palestra22.doc >. Acesso em: 11 jul. 2005.

MERTENS, D. R. Análise da fibra e sua utilização na avaliação e formulação de rações. Lavras: SBZ, 1992. p. 188-219.

MONTOYA, L. J. V.; MEDRADO, M. J. S.; MASCHIO. L. M. de A. Aspectos de arborização de pastagens e viabilidade técnicaeconômica da alternativa silvipastoril. In: SEMINÁRIO SOBRE SISTEMAS AGROFLORESTAIS NA REGIÃO SUL DO BRASIL, 1., 1994, Colombo. Anais... Colombo: EMBRAPA-CNPF, 1994. p. 157-172. (EMBRAPA-CNPF. Documentos, 26).

MONTOYA, L. J. V.; BAGGIO, J. A. Estudo econômico da introdução de mudas altas para sombreamento de pastagens. In: ENCONTRO BRASILEIRO DE ECONOMIAE PLANEJAMENTO FLORESTAL, 2., 1991, Curitiba, PR. Anais... Colombo: EMBRAPACNPF, 1992. v. 2. p. 171-190.

MOTT, G. O.; LUCAS, H. L. The design, conduct, and interpretation of grazing trials on cultivated and improve pastures. In: INTERNATIONAL GRASSLAND CONGRESS, 6., 1952, Pensylvania. Proceedings... Pensylvania, 1952. p.1380-1385.

NATIONAL RESEARCH COUNCIL. Nutrient requeriments of beff cattle. 7. rev. ed. Washinton, D.C.: 2000. 248 p. Disponível em: $<$ http://www.nap.edu/catalog/9791.html>. Acesso em: 03 out. 2010.

NORDGREN, A.; LOFVENIUS, O. M.; HÖGBERG, M. N.; MELLANDER, P. E.; HÖGBERG, P. Tree root and soil heterotrophic respiration as revealed by girdling of boreal Scots pine forest: extending observations beyond the first year. Plant, Cell and Environment, Oxford, n. 26, p. 1287-1296, 2003.
PACIULLO, D. S. C.; LOPES, F. C. F.; MALAQUIAS JUNIOR, J. D.; VIANA FILHO, A.; RODRIGUEZ, N. M.; MORENZ, M. J. F.; AROEIRA, L. J. M. Características do pasto e desempenho de novilhas em sistema silvipastoril e pastagem de braquiária em monocultivo. Pesquisa Agropecuária Brasileira, Brasília, DF, v. 44, n. 11, p. 1528-1535, nov. 2009. DOI: http:// dx.doi.org/10.1590/ S0100-204X2009001100022.

PALUDZYSZYN FILHO, E.; FERREIRA, C. A.; SANTOS, P. E. T. Eucaliptos indicados para plantio no Estado do Paraná. Colombo: Embrapa Florestas, 2006. 45 p. (Embrapa Florestas. Documentos, 129).

PORFÍRIO-DA-SILVA, V.; MORAES, A. D. Sistemas silvipastoris: fundamentos para a implementação. In: PIRES, A. V. Bovinocultura de corte. Piracicaba: FEALQ, 2010. v. 2. p. 1421-1455.

PORFÍRIO-DA-SILVA, V. Sistema silvipastoril (grevílea + pastagem): uma proposição para o aumento da produção do arenito do caiuá. In: CONGRESSO BRASILEIRO SOBRE SISTEMAS AGROFLORESTAIS, 1.; ENCONTRO SOBRE SISTEMAS AGROFLORESTAIS NOS PAÍSES DO MERCOSUL, 1., 1994, Porto Velho. Anais. Colombo: EMBRAPA-CNPF, 1994. v. 2, p. 291-298.

PORFÍRIO-DA-SILVA, V.; MEDRADO, M. J. S.; NICODEMO, M. L. F.; DERETI, R. M. Arborização de pastagens com espécies florestais madeireiras: implantação e manejo. Colombo: Embrapa Florestas, 2009. 48 p.

RANGEL, J. H. de A.; ALMEIDA, S. A.; MUNIZ, E.; GOMIDE, C. A. Sistema silvipastoril: uma alternativa para a produção de ruminantes. In: GOMIDE, C. A. de M.; RANGEL, J. H. A.; MUNIZ, E. N.; ALMEIDA, S.A.; SÁ, J. L.; SÁ, C. O. Alternativas alimentares para ruminantes II. Aracaju: Embrapa Tabuleiros Costeiros, 2008. p. 245-267.

REIS, H. A.; MAGALHÃES, L. L.; OFUGI, C.; MELIDO, R. C. N. Agrossilvicultura no Cerrado, região noroeste do Estado de Minas Gerais. In: CARVALHO, M. M.; ALVIM. M. J.; CARNEIRO, J. da C. (Org.) Sistemas agrossilvipastoris na América do Sul: desafios e potencialidades. Juiz de Fora: Embrapa Gado de Leite, 2007. p. 137-154.

RIBASKI, J. Sobrevivência e desenvolvimento da algaroba, plantada com e sem proteção, em área de capim-bufel sob pastejo. Petrolina: EMBRAPA-CPTSA, 1986. 4 p. (EMBRAPA-CPTSA. Pesquisa em andamento, 48).

SANTOS, A. C. A.; ROSSATO, M.; SERAFINI, L. A.; BUENO, M.; CRIPPA, L. B.; SARTORI, V. C. et al . Efeito fungicida dos óleos essenciais de Schinus molle L. e Schinus terebinthifolius Raddi, Anacardiaceae, do Rio Grande do Sul. Revista Brasileira de Farmacognosia, Curitiba, v. 20, n. 2, Apr./May 2010. DOI: http:// dx.doi.org/10.1590/S0102-695X2010000200003.

SANTOS, S. A.; COSTA, C.; SOUZA, G. S.; POTT, A.; ALVAREZ, J. M.; MACHADO, S. R. Composição botânica da dieta de bovinos em pastagem nativa na Sub-Região de Nhecolândia, Pantanal. Revista Brasileira de Zootecnia, Viçosa, MG, v. 31, p. 1648-1662, 2002. 
SCHREINER, H. G. Tolerância de quatro gramíneas forrageiras a diferentes graus de sombreamento. Boletim de Pesquisa Florestal, Colombo, v. 15, p. 61-72, 1987.

SHARROW, S. H. Effects of shelter tubes on hardwood tree establishment in western Oregon silvopastures. Agroforestry Systems, n. 53, p. 283-290, 2001.

SHIMIZU, J. Y.; CARVALHO, P. E. R. Primeira aproximação na indicação de eucaliptos para produção de madeira na Região de Quaraí, RS. Boletim de Pesquisa Florestal, Colombo, n. 40, p. 101-110, 2000.

SILVA, J. L. S.; SAIBRO, J. C.; CASTILHOS, Z. M. S. Situação da pesquisa e utilização de sistemas silvipastoris no Rio Grande do Sul. In: CARVALHO, M. M.; ALVIM, M. J.; CARNEIRO, J. C. (Ed.). Sistemas agroflorestais pecuários: opções de sustentabilidade para áreas tropicais e subtropicais. Juiz de Fora: Embrapa Gado de Leite; Brasília: FAO, 2001. p. 379-398.

SIMPOSIO INTERNACIONAL EM INTEGRACAO LAVOURAPECUARIA, 2007, Curitiba. Anais. Curitiba: Universidade Federal do Paraná; Universidade Federal do Rio Grande do Sul; Universidade do Estado de Ohio, 2007.
USDA. Silvopasture: integrating trees, forages and livestock. Missouri: NRCS, 2005. (Information Sheet -MO381). Disponível em: <www.mo.nrcs.usda.gov/technical/forestry>. Acesso em: 02 maio 2010.

VARELLA, A. C.; PORFIRIO-DA-SILVA, V.; SOARES, A.; MORAES, A.; SAIBRO, J. C.; POLI, C. H. E. C.; BARRO, R. S. Screening native and cultivated pasture for silvopastoral systems in Southern Brazil. In: CONGRESO NACIONAL SISTEMAS SILVOPASTORILES, 1., 2009, Posadas. Sistemas Silvopastoriles: una oportunidade para el desarollo sustentable, Posadas: Instituto Nacional de Tecnologia Agropecuaria, 2009. p. 363-367.

VELÁZQUEZ, E.; OURNIER, H. A.; BUSCHIAZZO, P. M.; SAAVEDRA, G.; SCHINELLA, G. R. Antioxidant activity of Paraguayan plant extracts. Fitoterapia, n. 74, p. 91-97, 2003.

VELOSO, H. P.; RANGEL FILHO, A. L. R.; LIMA, J. C. A. Classificação da vegetação brasileira adaptada a um sistema universal. Rio de Janeiro: IBGE, 1991. 123 p.

WILLIAMS, D. A.; OVERHOLT, W. A.; CUDA, J. P.; HUGHES, C. R. Chloroplast and microsatellite DNA diversities reveal the introduction history of Brazilian peppertree (Schinus terebinthifolius) in Florida. Molecular Ecology, n. 14, p. 3643-3656, 2005. DOI: 10.1111/j.1365-294X.2005.02666.x 